\title{
STIR and diffusion-weighted MRI in asymptomatic hyperCKemia caused by ANO5-related myopathy
}

\author{
Sequências de difusão e STIR na ressonância magnética em hiperCKemia assintomática \\ causada por miopatia associada ao AN05
}

André Macedo Serafim SILVA1', Júlio Brandão GUIMARÃES ${ }^{1,2}$, Flávia Costa Nunes MACHADO1,2, Edmar ZANOTELI1,2

A 16-year-old man presented with four years of persistent hyperCKemia (20x the upper limit of the normal level) without any symptoms. The neurological examination was normal. No relevant family history or consanguinity were reported. A whole-body muscle MRI revealed normal T1 images, but it depicted hyperintensity in the medial gastrocnemius muscles by short tau inversion recovery (STIR) and diffusion-weighted imaging (DWI) sequences (Figure 1). Next-generation sequencing showed two variants, c.191dupA and c.2294A>G, in the ANO5 that encodes anoctamin-5, a chloride channel important for muscle membrane repair ${ }^{1}$. Up to one-fourth of patients with recessive ANO5 mutations present with isolated hyperCKemia $^{2}$, and STIR/DWI hyperintensity can be the only relevant abnormality.

\section{References}

1. Bolduc V, Marlow G, Boycott KM, Saleki K, Inoue H, Kroon J, et al. Recessive mutations in the putative calcium-activated chloride channel Anoctamin 5 cause proximal LGMD2L and distal MMD3 muscular dystrophies. Am J Hum Genet. 2010 Feb; 86(2): 213-21. https://doi.org/10.1016/j.ajhg.2009.12.013

2. Silva AMS, Coimbra-Neto AR, Souza PVS, Winckler PB, Gonçalves MVM, Cavalcanti EBU, et al. Clinical and molecular findings in a cohort of ANO5-related myopathy. Ann Clin Transl Neurol. 2019;6(7):1225-38. https://doi.org/10.1002/acn3.50801
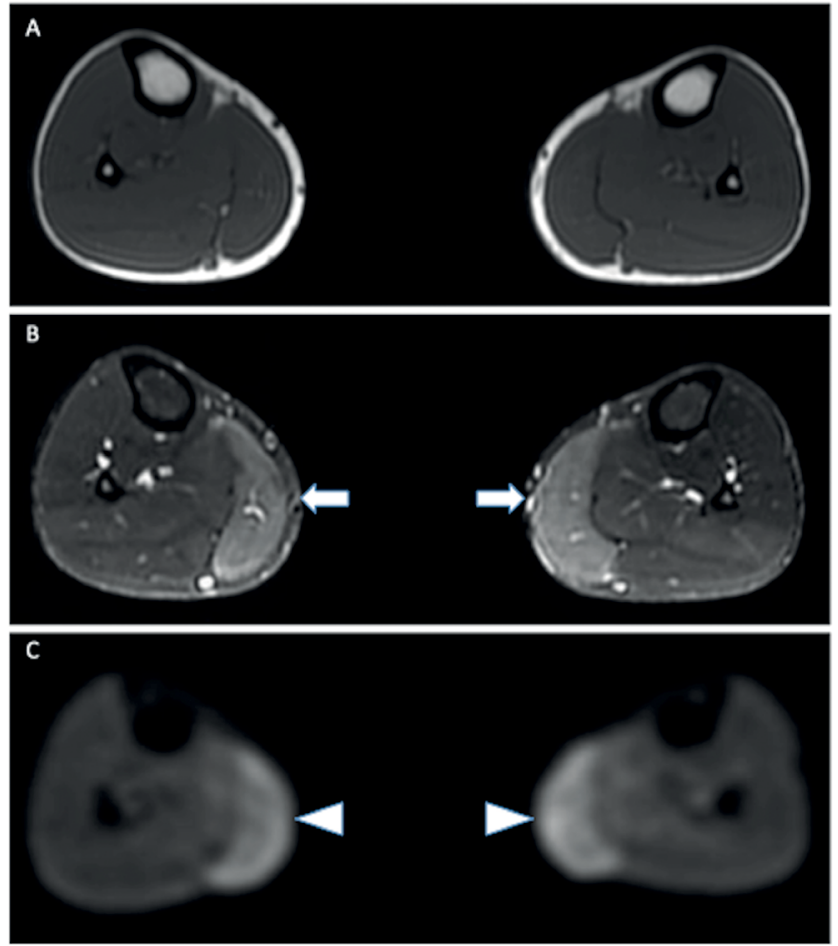

(A) Axial T1-weighted MRI of the legs shows no atrophy or fat infiltration (B) Axial STIR-weighted MRI of the legs demonstrates bilateral symmetric diffuse edema of the medial gastrocnemius muscles (arrows). (C) A b-value of $800 \mathrm{~s} / \mathrm{mm}^{2}$ diffusion-weighted WBMRI shows bilateral increased signal of the medial gastrocnemius muscles (arrowheads).

Figure 1. MRI in asymptomatic hyperCKemia with ANO5 recessive variants.

\footnotetext{
${ }^{1}$ Universidade de São Paulo, Faculdade de Medicina, Departamento de Neurologia, São Paulo SP, Brazil.

${ }^{2}$ Fleury Medicina e Saúde, São Paulo SP, Brazil.

André Macedo Serafim SILVA (D) https://orcid.org/0000-0002-5792-5878; Júlio Brandão GUIMARÃES ID https://orcid.org/0000-0002-5075-5896; Flávia Costa Nunes MACHADO (iD https://orcid.org/0000-0002-9316-501X; Edmar ZANOTELI (iD) https://orcid.org/0000-0002-4991-6760

Correspondence: André Macedo Serafim Silva; E-mail: andremacedo@usp.br

Conflict of interest: There is no conflict of interest to declare.

Author contributions:

Dr. Silva: Study concept, acquisition and analysis of data, literature review, and initial draft of the paper.

Dr. Guimarães: Acquisition and analysis of data, literature review, and critical revision of manuscript for intellectual content.

Dr. Machado: Acquisition and analysis of data, literature review, and critical revision of manuscript for intellectual content.

Dr. Zanoteli: Study concept, acquisition and analysis of data, literature review, and critical revision of manuscript for intellectual content.

Disclosures: Dr. Silva, Dr. Guimarães, Dr. Machado, and Dr. Zanoteli report no disclosures relevant to the manuscript.

Received on February 10, 2020; Received in final its form on February 10, 2020; Accepted on March 23, 2020.
} 